\title{
Investigar en un mundo encantado: los aportes de las metodologias indigenas al quehacer etnográfico ${ }^{1}$
}

\author{
Giovanna Micarelli ${ }^{2}$ \\ Pontificia Universidad Javeriana, Colombia \\ giomica@gmail.com \\ Recibido: 8 de agosto de 2017 \\ Aceptado: 15 de mayo de 2018 \\ Disponible en línea: 28 de diciembre de 2018
}

1 Este artículo de reflexión se basa en varios procesos de investigación llevados a cabo en el Trapecio Amazónico desde 1998, y financiados por una beca doctoral de la Wenner-Gren Foundation for Anthropological Research (1998-2000) y una beca postdoctoral de la Spencer Foundation for Research in Education (2004-2007). Los proyectos indígenas de los que hablo en el texto fueron apoyados por una beca del Fondo Mixto - Ministerio de Cultura y por la Secretaría de Salud Municipal de Leticia.

2 M.A. y Ph.D, University of Illinois at Urbana-Champaign. Antropóloga, Universidad de Roma "La Sapienza". Profesora, Departamento de Antropología, Pontificia Universidad Javeriana. Investigadora, Centro de Estudios Sociales, Universidad de Coimbra (Portugal). 


\title{
Investigar en un mundo encantado: los aportes de las metodologias indigenas al quehacer etnográfico
}

\section{Resumen}

Tomando en consideración las metodologías de la Gente de Centro de la Amazonía colombiana, este ensayo busca sustituir una noción de la práctica etnográfica como conjunto de técnicas de extracción de datos, con un compromiso con otras prácticas cognitivas que acate los modos en que el conocimiento se produce y se valida localmente. A través del relato de dos proyectos de investigación indígena, el texto sugiere que el método moderno desencantado -con sus "entrevistas semi-estructuradas", sus grupos focales y sus diseños de recolección de datos- es inadecuado para dar cuenta de un mundo en que todo habla y lo hace de manera inesperada. A la vez, la advertencia de los indigenas de vigilar los efectos del conocimiento sobre el mundo, nos obliga a asumir una actitud responsable hacia el mundo que el acto de conocer produce o puede producir. La pregunta es: ¿cómo estas metodologias que surgen del diálogo intercultural contribuyen a descolonizar el quehacer etnográfico? Palabras clave: metodologías y epistemologías indígenas; Amazonía colombiana; Gente de Centro

\section{Research in an enchanted world: the contributions of indigenous methodologies to ethnographic practice}

\begin{abstract}
Based on the methodologies of the indigenous Gente de Centro (People of the Center) of the Colombian Amazon, this essay seeks to replace a notion of ethnographic practice as a set of techniques for data extraction, with a commitment with other cognitive practices that accepts the ways in which knowledge is produced and validated locally. Through the narrative of two indigenous research projects, the text suggests that the disenchanted modern method -with its "semi-structured interviews", focus groups, and data collection designs- is inadequate to account for a world where everything speaks, and does so in unexpected ways. At the same time, the warning of indigenous people to monitor the effects of knowledge on the world compels us to assume a responsible attitude towards the world that the act of knowing produces, or can produce. The question is how do these methodologies, emerging from intercultural dialogue, contribute to decolonize the ethnographic work? Keywords: indigenous methodologies and epistemologies; Colombian Amazon; Gente de Centro
\end{abstract}

\section{Pesquisa em um mundo encantado: contribuições das metodologias indigenas ao quefazer etnográfico}

\section{Resumo}

A levar em consideração as metodologias da Gente de Centro da Amazônia Colombiana, este ensaio visa substituir uma noção da prática etnográfica como conjunto de técnicas de extração de dados, com um compromisso com outras práticas cognitivas que aceita os modos em que o conhecimento é produzido e validado localmente. Através do relato de dois projetos de pesquisa indígena, o texto sugere que o método moderno desencantado -com suas "entrevistas semiestruturadas", seus grupos focais y seus desenhos de coleta de dados- é inadequado para dar conta de um mundo em que tudo fala e o faz de maneira inesperada. Ao mesmo tempo, a advertência dos indígenas de vigilar os efeitos do conhecimento sobre o mundo nos incita a assumir uma atitude responsável com o mundo que o fato de conhecer produz ou pode produzir. A pergunta é: como essas metodologias surgidas do diálogo intercultural contribuem para descolonizar o quefazer etnográfico?

Palavras-chave: metodologias e epistemologias indígenas; Amazônia colombiana; Gente de Centro 
- Abuelo ¿puedo grabar?

-Puedes, pero la parte profunda la grabadora no la coge.

Conversación con un indígena Uitoto Muina.

“¿Para qué quieres conocer?”. Pregúntale algo a un indígena de la Gente de Centro y es muy probable que eso sea lo que te responda. Este metamensaje, que advierte que hay mucho más en juego que simple información, me ha ido interpelando sobre los fines de la investigación y sobre el conocimiento en general.

Cuando comencé a trabajar con los pueblos indígenas de Amazonía compartía el posicionamiento de una antropología crítica y políticamente comprometida para la cual no hay que limitar la investigación a un ejercicio académico, sino contribuir con ella a las luchas culturales y políticas de los grupos con quienes trabajamos. Esta posición inicial se ha ido problematizando en el proceso de aprender de los indígenas, en la medida en que se hizo evidente el sesgo implícito, un poco arrogante y paternalista, de concebir la investigación como una relación asimétrica, y su supuesta contribución como unidireccional. Esta asimetría solo puede ser desarmada subvirtiendo el orden en que se funda y tomando en serio la cuestión: ¿cómo las prácticas cognoscitivas indígenas pueden contribuir a transformar la investigación y volverla más capaz de responder a los desafios sociales actuales? Esta cuestión es sugerida tácitamente por la pregunta "¿para qué quieres conocer?” que, además de una indagación sobre las motivaciones del interlocutor, es una invitación a participar de una particular visión del conocimiento; sus métodos y fines y no solo sus contenidos. Le sigue la advertencia: "esto no es para hacer daño, para humillar, para dominar a los demás, para enriquecerse, para que lo archives...". Preguntar es cosa seria; tiene casi un peso contractual o por lo menos compromete.

Desde su institucionalización como método central de la antropología, la práctica etnográfica se ha hallado en la encrucijada de dos caminos, que pueden resumirse como "conocer sobre" o "conocer con". Mientras el primer camino supone una separación 
jerárquica entre el sujeto y el objeto del conocimiento que limita las posibilidades de una transformación tanto epistemológica como política, el segundo propende por una relación de aprendizaje simétrico en la que los métodos y objetivos de la acción de conocer pueden resultar profundamente trastocados. Este texto sostiene que la posibilidad de la antropología de ser un "ejercicio permanente de descolonización del pensamiento" (Viveiros de Castro, 2010, p. 24) reside en la disposición del o de la investigadora para permitir que otras formas de conocer ocupen el ámbito aséptico del método y lo fertilicen. La apuesta es sustituir una noción del quehacer etnográfico como conjunto de técnicas de extracción de datos, con un compromiso con otras prácticas cognitivas que acate los modos en que el conocimiento se produce y se valida en otros ámbitos culturales.

Tomo como punto de partida las metodologias de investigación de la Gente de Centro $^{3}$ de la Amazonía colombiana. Igual que para la ciencia occidental, para la Gente de Centro todo proceso de investigación también debe comenzar con la definición de unos objetivos. La finalidad del conocimiento, sin embargo, no es tanto explicar la realidad social, como contribuir al bienestar generalizado. Cuando no es así -los indígenas advierten- se está boleteando el conocimiento, y las consecuencias pueden ser catastróficas. Durante el proceso de investigación se presta particular atención a los mensajes del mundo -sonidos de animales, cambios atmosféricos, sueños y malestares- que informan sobre el estado de salud del grupo social y del territorio sobre el que el conocimiento tiene influencia directa. Inhalar humo de ají, bañarse con agua de hierbas aromáticas, consumir sustancias como la coca, el tabaco y la cahuana de almidón de yuca, dietar o quedarse quietos por horas en posición sentada, son aspectos centrales del método de investigación indígena. Estas prácticas corporales tienen como fin cultivar

\footnotetext{
La Gente de Centro es un conjunto supraétnico lingüísticamente diverso, pero bastante uniforme culturalmente, que incluye a los Uitoto, Bora, Miraña, Muinane, Andoke, Nonuya, Ocaina y Resigaro. Comprende aproximadamente a 7500 individuos que habitan en las regiones de Caquetá, Putumayo y Amazonas, de Colombia, y en la región amazónica del norte del Perú. Mi colaboración con la Gente de Centro comenzó en 1998 en el resguardo TikunaUitoto, Kilómetros 6 y 11, en el municipio de Leticia. Si bien el territorio ancestral de la Gente de Centro se ubica en el interfluvio Caquetá-Putumayo, a partir de los años 50, familias de la Gente de Centro se han ido reasentando, paulatinamente, en el actual territorio del resguardo, a raíz de la masacre cauchera, el conflicto armado y la búsqueda de mejores servicios en educación y salud.
} 
la atención plena y lograr un acoplamiento sensible con el mundo: "el mundo avisa, hay que saberlo entender". Es por esta razón también que los temas a abordar van de acuerdo con la hora y el lugar, algo que suscita intensas negociaciones con los funcionarios de las instituciones y que puede dejar sin respuesta las preguntas de la antropóloga.

Los indigenas investigan por muchas razones: para reivindicar derechos, ordenar, permanecer, dar a conocer y, claramente, por el gusto muy humano de hacerlo. Investigar se ha vuelto también una forma de captar recursos del Ministerio de Cultura $\mathrm{u}$ otras instituciones, que han ido paulatinamente destinando fondos para apoyar investigaciones indígenas, así como de ONG o de proyectos de investigación académica. El término 'investigación indigena' abarca, por ende, diversas prácticas en las cuales pueden o no participar profesionales "blancos", con roles variables y no exclusivos, desde proponer y/o financiar la investigación, hasta servir de intermediarios, asesores, acompañantes o aprendices. Es evidente que las investigaciones indígenas pueden surgir de circunstancias que no son necesariamente endógenas: una convocatoria o un proyecto académico o institucional. Pese a ello, una "investigación indígena" es aquella que ocupa el lugar exógeno de un proyecto, lo captura y lo transforma de acuerdo con sus propias metodologias, finalidades y criterios de evaluación. Esta apropiación puede ser el resultado de negociaciones más o menos intensas con quienes controlan, o quisieran controlar, el proyecto. Pero a menudo se despliega en un nivel encubierto, paralelo al nivel manifiesto de los cronogramas, objetivos, productos y demás requisitos que hay que cumplir.

Las maniobras ingeniadas por los indígenas para tomar control de la investigación revelan sin duda estrategias de resistencia frente al poder disciplinario ejercido por el conocimiento occidental. En un nivel más profundo, lo que revelan es una compleja teoría y método del conocimiento, es decir, una epistemología. Esto requiere a quienes participan en la investigación prestar atención simultánea a dos niveles distintos y sin embargo inseparables: el 
nivel de los contenidos y el nivel de la praxis investigativa. Voy a brindar como ejemplos dos proyectos de investigación indígena llevados a cabo en el Resguardo Tikuna-Uitoto, Kilómetros 6 y 11 (municipio de Leticia), entre 1998 y 2000, los primeros en los que participé como coinvestigadora y que retaron mis supuestos sobre el quehacer etnográfico, marcando un punto de giro hacia las reflexiones que presento aquí.

\section{"Mira tu cuerpo": la 'IAP' como investigación-actuación poética}

A finales de 1998, el Fondo Mixto de Leticia anunció una convocatoria para financiar proyectos de investigación sobre el tema "Historias de la vida cotidiana". En una región de empleos precarios, el anuncio de una beca nunca pasa desapercibido y moviliza rumores e información que activan redes oblicuas y temporales de alianzas y antagonismos. En ese tiempo yo estaba ocupada realizando mi investigación doctoral sobre las instituciones de desarrollo en la ciudad, así que no presté mayor atención a la convocatoria. Un día, un amigo que colaboraba ocasionalmente con la comunidad Nïmaira Naimekï Ibïrï (Kilómetro 11), me dijo incidentalmente que un grupo de líderes indigenas buscaba a alguien que les ayudara a conceptualizar y redactar una propuesta para el Fondo Mixto: "Espero no te importe si les sugerí que hablaran contigo". Tiempo después, me di cuenta de que les había dicho lo mismo a los compañeros indígenas. Así fue que nuestras conversaciones comenzaron a converger, de una manera un tanto torpe, sobre el tema "historias de la vida cotidiana", y, dia tras día, nos quedamos cada vez más envueltos en la discusión. Cuando finalmente nos dimos cuenta de que nuestro amigo común nos había hecho trampa, estábamos tan metidos en el tema que no podíamos sino escribir y presentar la propuesta. La decisión se formalizó con mambe y ambil preparados para la ocasión, y la propuesta recibió el nombre de: Historias de la vida cotidiana en la comunidad indigena Nïmaira Naimekï Ibïrï - Muina Murui, Kilómetro 11, con 
relación a la interculturalidad. Más mambe y ambil fueron preparados para atrapar a esa presa moderna, algo que resultó ser efectivo, ya que la presa cayó en la trampa y nos ganamos la beca. ${ }^{4}$

E1 proyecto tomó forma gracias a varios eventos que tuvieron lugar en los meses anteriores. En 1996, el cacique de la maloca del Kilómetro 11 llegó a la conclusión de que una de las causas de la desintegración de las comunidades indígenas en el Resguardo -conflictos internos, violencia, adicción, alcoholismo, pobreza y demás- fue haberse reubicado en un territorio que pertenece tradicionalmente a la jurisdicción de la etnia Tikuna sin pedir permiso a sus dueños espirituales. Para hacer amistad con los espíritus tikuna y así "curar el territorio", el cacique tomó la decisión de realizar una serie de rituales de baile que contaron con la participación de las parcialidades del Resguardo y representantes de comunidades Tikuna de toda la región. Esta estrategia restableció un orden ritual desde el cual manejar las relaciones interculturales en y con el territorio.

Otro evento importante fue la elección en 1998 del progresista Arcesio Murillo a la Gobernación del Departamento del Amazonas. Su programa, llamado Agenda 21, buscaba poner en práctica las resoluciones de la Conferencia de Río de Janeiro sobre medio ambiente y desarrollo, con un énfasis en la participación ciudadana. Por primera vez, el Plan Departamental de Desarrollo fue el resultado de amplias consultas con los diferentes sectores de la sociedad civil e incorporó los planes locales que cada sector había producido. ${ }^{5}$

El mismo año, en el marco de la guerra contra las drogas respaldada por los Estados Unidos, el ejército comenzó a irrumpir en los resguardos para arrancar las plantas de coca, hecho que fue percibido por los indígenas, con razón, como una violación de

4 La Gente de Centro a menudo concibe los proyectos de desarrollo como presas que son cazadas mediante el poder espiritual de la coca y, sobre todo, del tabaco (véase Micarelli, 2015b).

5 El gobierno de Murillo tuvo que enfrentarse a una enorme oposición de sus adversarios, en su mayoría terratenientes y empresarios que a menudo operan al margen de la ley. Utilizando cualquier medio posible, incluyendo amenazas, los adversarios de Murillo pudieron, eventualmente, hacia fines de 1999, forzarlo a salir de su cargo. 
sus derechos constitucionales. Históricamente, los indígenas han estado involucrados, queriendo o no, en cada una de las bonanzas extractivas de Amazonía, atraídos por la promesa de buenos ingresos, pagados la primera vez, y luego atrapados en un vicioso círculo de endeude. Durante los años ochenta, y hasta principios de los años noventa, el Resguardo proveyó mano de obra para el proceso de producción de cocaína. Hombres y mujeres fueron trasladados a zonas remotas de la selva, a cientos de kilómetros de Leticia, donde trabajaban durante unos meses en el procesamiento de pasta básica y luego eran enviados de regreso al Resguardo. Las consecuencias catastróficas del negocio de la cocaína para los pueblos indígenas de la región, la espiral de abyección causada por la violencia, la prostitución, la adicción, la ilegalidad, junto con la estigmatización de la planta de coca, desencadenaron una respuesta que se aferró a la coca como símbolo de resiliencia y como remedio.

En este escenario, el proyecto presentado al Fondo Mixto tenía el objetivo de proporcionar una mejor comprensión de las causas de los problemas que afectaban a la parcialidad del Kilómetro 11 y plantear estrategias para resolverlos. El primer paso fue analizar las relaciones interculturales a través de las historias del asentamiento y del proceso de apropiación de un nuevo territorio en un contexto marcado por la diversidad sociocultural. El objetivo de este análisis histórico, era, según los investigadores indígenas, construir una visión actualizada de la sociedad indígena, un paso que consideraban indispensable para fortalecer su capacidad de organización y toma de decisiones con respecto a las políticas del Estado, particularmente los marcos de multiculturalismo, descentralización y ordenamiento territorial. A través de un enfoque en la interculturalidad, la investigación buscaba identificar formas alternativas de organización, gobierno y administración en una comunidad multiétnica como el Kilómetro 11. El proyecto entendía la interculturalidad desde una crítica al desarrollo como modelo impuesto para resolver los problemas de la parcialidad, preguntando cómo el desarrollo se había introducido en la parcialidad, cómo regulaba la vida diaria, por qué fracasó, qué efecto tuvo en 
los procesos identitarios, en la subjetividad y en el lugar atribuido a los indígenas en la sociedad local y nacional. Los líderes sostenían que a pesar de las buenas intenciones, el desarrollo no promovía el autogobierno, ni la autodependencia ni la participación plena de las comunidades; las personas todavía dependían de las instituciones para definir su idea de desarrollo y esto entorpecía los procesos endógenos de gobierno propio. "Nos faltan modelos", decía uno de los investigadores Muina. "Este es el problema de hablar dos idiomas. Cuando usamos uno, nos olvidamos del otro", agregó. Una de las principales preguntas del proyecto fue cómo mediar entre lo propio y lo ajeno. Este objetivo se plasmó en las actividades planeadas, que incluyeron una comparación entre las comprensiones institucionales y locales de conceptos tales como familia, comunidad, territorio y economía, y la elaboración de mapas que permitieron visualizar los recursos humanos y naturales de la parcialidad y las relaciones territoriales. Esta información alimentó el diseño del Plan de Ordenamiento Territorial y fue incorporada en el currículum de la escuela. De hecho, una de las preocupaciones de los investigadores era que una educación descontextualizada como la que se lleva a cabo en la comunidad no puede responder ni contribuir al desarrollo de la parcialidad, ya que no cultiva aquellos saberes y prácticas que garantizan una relación sana entre los humanos y su entorno.

Uno de los objetivos del proyecto era identificar las prerrogativas de cada clan y linaje representado en la comunidad, ya que esta información se consideraba crucial para generar estrategias propias de autoadministración. Por consiguiente, el equipo de investigación fue constituido por dos ancianos y dos jóvenes líderes, padres e hijos pertenecientes a dos linajes de los grupos Muina y Murui, respectivamente. Entre la Gente de Centro, clanes y linajes detienen conocimientos especializados y están marcados por derechos y deberes exclusivos. El argumento del grupo para rescatar este sistema insistió en que se trata de un método de organización del trabajo que diverge de las formas de organización introducidas por el estado. En las comunidades multiétnicas, resultado de la diáspora de la bonanza cauchera y de las políticas estatales, 
esta divergencia se convierte en un obstáculo para la organización social. Como decía un anciano: “¿Cómo voy a hacerle caso a ese gobernador si tengo que respetar el linaje de cacicazgo que pertenece a mi linaje murui?". Los proyectos de desarrollo, canalizados a través del cabildo y dirigidos a una supuesta "comunidad" indiferenciada, no ayudan a reconstruir este sistema de organización. Al contrario, ignorándolo por completo no solo fracasan, sino que también se convierten en una fuente de conflictos. Este primer aspecto de la estrategia metodológica puesta en acto por el grupo tiene implicaciones importantes para repensar la manera en que negociamos el acceso a una "comunidad", muy a menudo a través de funcionarios públicos de la administración local. En general, desdibuja "la comunidad indígena" en cuanto objeto de la representación.

Uno de los requisitos del Fondo Mixto era que el beneficiario de la beca contratara a un supervisor del proyecto -el interventory le pagara el $10 \%$ de la suma recibida. El interventor debe mediar entre los beneficiarios de la beca y la institución, controlando que el proyecto cumpla con los objetivos y los plazos establecidos y produciendo periódicamente las recomendaciones de las cuales depende el pago de las cuotas sucesivas. Evidentemente, se trata de una figura que conduce al soborno, y a menudo se entregan las interventorias a cambio de favores. ${ }^{6}$ Para evitar este escenario y tener mejores posibilidades de completar la investigación en sus propios términos, el grupo decidió contratarme a mí como interventora. Mi responsabilidad era monitorear la investigación y asegurarme de que los objetivos del proyecto se cumplieran de acuerdo con el cronograma.

En este momento, algo empezó a ocurrir de manera sistemática cuando trataba de programar una reunión con el grupo de investigadores. Después de fijado un horario, ellos, o no aparecían, o llegaban horas más tarde, o antes, o incluso otro día. La nuestra era una relación de amistad y confianza y, en otras ocasiones, cuando

6 El mecanismo es el siguiente: un funcionario corrupto escoge al interventor entre sus amigos, este emite un concepto negativo que detiene los desembolsos siguientes, y los fondos desviados se reparten entre los compinches. 
habíamos quedado en encontrarnos, habían llegado puntuales en el horario pactado. Pero esto no funcionaba para el proyecto. Cuando trataba de plantear cuestiones relacionadas con la investigación durante encuentros informales, ellos objetaban que no era el momento ni el lugar adecuado para hablar de ello. Todo tenía que ser fijado por adelantado, y coca y tabaco especialmente preparados para la ocasión. Así que traté de seguir un procedimiento más formal: les ofrecí tabaco en la maloca la noche anterior a la reunión, recordándoles los temas a discutir; hasta les envié cartas de invitación con copia de recibo. Nada funcionaba. Había algo que no lograba entender: una especie de declaración de independencia frente al control del tiempo establecido por la institución financiadora que de cierta manera yo representaba.

Había comenzado a darme cuenta de que los temas y tipos de discurso dependen de lugares y momentos específicos del día. La oposición entre la noche y el día marca una oposición más profunda entre la filosofia nativa del habla, por un lado, y el discurso de las instituciones, por el otro. La hora y el lugar para discutir temas importantes es después de la medianoche, en la maloca, "cuando el pilón queda silencio" (es decir, ha dejado de machacar las hojas de coca). La palabra pronunciada en la noche en el mambeadero recoge todo lo que ha ocurrido durante el día y lo teje en un "canasto" de experiencia. Además, esta palabra nocturna tiene el poder de materializarse e influir en los acontecimientos diarios, así que es objeto de cuidado. Esto es aún más así, ya que:

Ir al origen de la historia de la comunidad es un tema delicado. [...] Es una fuente de conflictos. Hay competencia entre clanes, porque hay clanes que mantienen el conocimiento, y clanes que no. Hay cosas que no pueden ser nombradas, como Moniya Amena, ${ }^{7}$ que, de hecho, ahora está cambiando su nombre.

\footnotetext{
Moniya Amena es la comunidad indígena del Kilómetro 9, cuyo nombre, que significa el árbol de la abundancia de la mitología uitoto, fue considerado por algunos demasiado "caliente" por su asociación con los mitos de origen. Por esta razón la comunidad adoptó durante algunos años el nombre de Manaide Izuru ("canal frío"), para después, en tiempos más recientes, volver a llamarse Moniya Amena.
} 
Antes que ser algo negociable, el horario se convirtió en un campo de disputa entre distintas temporalidades, agencialidades y formas de organización. De esta manera, el grupo trataba de afirmar su autonomía con respecto a una serie de suposiciones fundamentales del desarrollo y de la temporalidad de la modernidad occidental. Resistiendo el control ajeno del tiempo y el espacio, el grupo estaba metonímicamente negando todo ese mundo y su poder de moldear percepciones y prácticas diferentes.

Las conversaciones nocturnas que sentaron las bases de la propuesta de investigación revelaron la importancia del concepto de 'trabajo' en las epistemologías indígenas. En una perspectiva compartida con otras sociedades indígenas amazónicas, para la Gente de Centro el trabajo encarna y materializa el pensamiento intencional y el habla, y abarca ámbitos tan diversos como el chamanismo, la producción de alimentos, la enseñanza-aprendizaje y la curación (Micarelli, 2015a). Todas estas actividades son fundamentales en la fabricación de cuerpos sociables y en la reproducción de la vida en general (Griffiths, 2002). Los hábitos del trabajo son fuente de identidad verdadera y es por medio del trabajo que se mantiene activo el intercambio de energía vital a través de una red de relaciones socioambientales. La Gente de Centro no habla de investigación, sino de trabajo: "Yo no hago investigación ¡Yo trabajo!”, replicaba una mujer cuando le pregunté por su investigación de los cantos de los rituales de baile. El conocimiento es "para vivir y sentirlo" y esto se logra mediante el trabajo; no meramente se incorpora, sino que da forma a un cuerpo; es su misma sustancia. Otra mujer anciana, mostrándome las manos y golpeándose la cabeza, las piernas, las rodillas, me decia: "iMira! Yo tengo mucho, ¡mucho conocimiento!”.

Para la Gente de Centro, el cuerpo es la sombra de los antepasados y de las generaciones futuras. Los mundos pasados y futuros se reflejan en él. El cuerpo humano lleva los rastros sensibles de las generaciones, de las enfermedades pasadas por alto y de las potencialidades por desentrañar; las enfermedades se convierten en epidemias y las potencialidades se echan a perder a menos que el pensamiento intencional, el habla y el trabajo las acometan y 
transformen, orientando este esfuerzo hacia el bienestar generalizado. Un hecho significativo, en un cierto punto del desarrollo del proyecto, fue la decisión de los ancianos de nombrarlo nuevamente. El nuevo nombre fue: o abïmo erokaï-"mira tu cuerpo"-, que se refiere a un mito de la Gente de Centro en el que el creador, en el proceso de materializarse, mira su cuerpo y se da cuenta de que es persona. Este acto del habla estableció el proyecto como un proceso de autorreconocimiento y de autoformación, del cual se desprende el objetivo de curar y traer abundancia. Curar el cuerpo es el primer paso para curar la historia también. En el cuerpo humano, el pasado y el futuro se muestran como sombras borrosas, y es a través de la agencia humana que adquieren forma tangible. Así que el cuerpo humano no es solo la imagen reflejada de la historia, sino que se refleja de vuelta en la historia.

Podemos decir que el método de investigación indígena consistió en una IAP, pero no en el sentido de investigación-acción participativa, sino de "investigación-actuación poética" que, a la vez que investiga, recrea la identidad. Esta no es algo que pueda ser recuperado del pasado, sino algo dialécticamente creado y negado diariamente, "desencadenado por disyunciones en las interacciones sociales y ambientales" (White, 2002, p. 1). Ese proceso -a la vez profundamente histórico y que refleja un tipo particular de historicidad-se sitúa en la disyunción entre presencia y ausencia. La presencia puede perder su agarre; uno puede sentirse dislocado e incapaz de actuar y resuelve echar amarras en el pasado o ser arrojado a un futuro dificil de imaginar. La ausencia, por otra parte, se hace presente a través de la memoria y la imaginación. El modelo de la ciencia responsable de la Gente de Centro -"pensar bien, hablar bien y trabajar bien, para convertirlo en abundancia para todos"-, se asienta en esta disyunción, y se esfuerza por hacer lo irreal posible. Al mismo tiempo, orienta a la Gente de Centro a evaluar, resistir y transformar los regímenes de conocimiento ajenos, como aquellos empleados por el aparato del conocimiento técnico y burocrático del desarrollo. De esta manera, los modos nativos de pensar y hacer lograron infiltrarse en un género ajeno, como "el proyecto", y apropiárselo. El proyecto se convirtió en un escenario para afirmar percepciones del tiempo, la agencia, el 
conocimiento y el trabajo, alternativas a aquellas impulsadas por la modernidad occidental. La Gente de Centro estaría de acuerdo con Maturana y Varela (1984, p. 26) en que el conocimiento del conocimiento obliga, y que "todo hacer es conocer, todo conocer es hacer [...]. Esta circularidad, esta inseparabilidad entre una forma particular de ser y cómo el mundo se nos aparece, nos dice que cada acto de conocimiento produce un mundo".

\section{Humo de aji, agua de hierbas frias: investigar en un mundo encantado}

El segundo proyecto surgió de mi colaboración con un indígena muinane, lo llamaré aquí Ramón, formado como promotor de salud tanto en el sistema médico indigena como occidental. Cuando lo conocí, Ramón acababa de llegar del Caquetá después de trabajar varios años como promotor para la Secretaría de Salud Departamental. En su trabajo como promotor, Ramón había comprobado que la ineficacia de los programas institucionales de promoción y prevención en las comunidades indígenas del Departamento, y el deterioro de la salud entre los indígenas en general, se debe a razones tanto externas como internas, entre las cuales están el desconocimiento de los sistemas indígenas de promoción y prevención por parte de la Secretaría, la falta de inclusión de estos conocimientos en la formación de los promotores, la no articulación o incluso la discrepancia entre las aproximaciones indigenas y occidentales a la salud, la rivalidad entre expertos locales y promotores de la institución, la desvaloración y la pérdida de los conocimientos culturales sobre promoción y prevención en las sociedades indígenas. Durante más o menos un año colaboramos para redactar una propuesta de investigación cuyo objetivo era integrar las perspectivas indígenas sobre promoción y prevención de la salud en el programa de formación de promotores de la Secretaría de Salud Departamental y, al mismo tiempo, fortalecer la educación para la salud en las comunidades indígenas del Amazonas. ${ }^{8}$

8 Este trabajo fue recopilado en el texto Cultivando el árbol de la ciencia de la salud, de próxima publicación con la Editorial Javeriana. 
Ramón siempre hizo hincapié en que la información que me estaba pasando era "encimita no más", dejando en claro que no podía considerarme su aprendiz, por diferentes razones. El conocimiento se transfiere a través de líneas genealógicas y este aprendizaje exige un compromiso de muchos años, durante el cual el aprendiz tiene que cumplir reglas estrictas, viviendo a veces una vida aislada, y pasando una serie de pruebas que determinarán su camino de conocimiento. Cualquier desviación pone en peligro de vida al aprendiz, su maestro y sus familias extendidas, así que excluirme formalmente del aprendizaje era una manera de protegernos a ambos del poder peligroso, inherente al conocimiento de la salud y de la enfermedad. Una persona que no tiene conocimiento del mundo espiritual "solo se alimenta de cosas materiales y sigue un camino material, sin ningún compromiso". Tan pronto una persona comienza a aprender "cosas del mundo espiritual", destapa los poderes contenidos en ese mundo y se convierte en su blanco. Por su sustancia mítica cosmogónica, el conocimiento es "caliente" y es una fuente potencial de enfermedades. Al "destaparlo" hay que saber cómo enfriarlo. Tanto el maestro como el aprendiz comparten la responsabilidad de vigilar incesantemente al mal, controlando y poniendo barreras en los caminos por donde este llega: las enfermedades, los conflictos, el hambre, la locura.

Ramón y yo trabajábamos sobre todo en la noche, cuando el calor del día y de las actividades cotidianas se enfría y el mundo queda tranquilo. Sin embargo, "el mal nunca duerme", y la búsqueda del conocimiento es un trabajo plagado de obstáculos: pereza, negligencia, defensas inadecuadas, comportamiento y palabra incorrectos, pensamiento torcido. El enemigo más poderoso es la "presión del mundo", el lado oscuro del conocimiento: la búsqueda del poder personal. Nociones de agencia y responsabilidad impregnan la visión del conocimiento de la Gente de Centro. Como sugieren los filósofos indígenas Vine Deloria Jr. (1999) y Lee Hester (Hester y Chaney, 2001) refiriéndose al contexto norteamericano, los indígenas no tratan el conocimiento como un tipo de creencia que puede ser falsa o verdadera, sino más bien como un mapa que guía la acción. El conocimiento verdadero no es definido en 
términos abstractos, sino a partir de la evaluación de sus efectos tangibles en el mundo y la experiencia humana. El conocimiento verdadero apunta al bienestar generalizado, mientras que el falso conocimiento apunta a acumular poder personal sobre los demás; esta acumulación desequilibra el flujo de energía vital y se convierte en una fuente de desventura.

Antes de comenzar a trabajar en la propuesta, Ramón decidió que necesitaba someterme a un tratamiento de limpieza. Conjuró ambil, ají y palo fósforo, que preparó para este fin, más tabaco e incienso que me mandó a comprar en una tienda esotérica atendida por indígenas inganos en el puerto fluvial. El ambil -pasta de tabaco mezclada con sal vegetal y otros aditivos- tiene potentes efectos eméticos y purgantes, mientras que el humo de ají y el palo fósforo provocan secreción profusa, limpiando el seno nasal y dando realmente la sensación de una mente despejada. Ramón hacía especial hincapié en la necesidad de bañarse después de nuestras reuniones, enfriando antes del sueño el calor producido por el trabajo de pensar. Como cualquier trabajo, pensar produce suciedad que tiene que ser eliminada para que no se convierta en enfermedad. Cuando no es posible tomar un baño, hay que rociar agua en la frente, las orejas y la parte posterior de la cabeza, donde se almacenan los recuerdos. También hacía especial hincapié en la dieta: no solo evitar determinados alimentos y reducir la ingesta de alimentos en general, sino también evitar la rabia y los chismes, trabajar con ánimo y mantener un humor alegre y positivo.

En el proceso de enseñanza y aprendizaje se presta particular atención a las cualidades materiales del cuerpo y los sentidos y se emplean prácticas corporales reguladoras, tales como el vómito, la limpieza con hierbas aromáticas, la inhalación de humo de ají o de otras plantas, las dietas, la restricción del sueño, del movimiento, del habla y de las relaciones sexuales. Estas disciplinas se conciben como formas de "educar al cuerpo" y de "despejar a la mente". Educar el cuerpo no significa reprimirlo para que la mente pueda vagar libremente, sino sintonizar percepción e introspección. Sentarse en posición erecta, inmóvil, durante largos periodos de 
tiempo en casi completa oscuridad, tranquilizar la respiración y la mente es una actividad del cuerpo-mente cuyo propósito es lograr la consciencia plena (Varela, Thompson y Rosch, 1991, p. 23). Un cuerpo educado es un cuerpo plenamente consciente de sus componentes materiales e inmateriales, un "cuerpo físico-espiritual", como lo llama Ramón, capaz de lograr un acoplamiento consciente con el mundo. Esta disciplina es una "medicina preventiva, porque no deja entrar al mal" y, al mismo tiempo, agudiza los sentidos y los hace capaces de "detectar la enfermedad a distancia".

La investigación para la promoción de la salud implica captar e interpretar señales elusivas en el cuerpo y en el entorno con el fin de identificar el agente causal de la enfermedad. Ramón describe esta información comparándola con el flujo de mensajes que aparecen en un letrero electrónico. Estos signos son físicos y psicológicos, externos e internos. "Todo en el mundo habla"; sonidos de animales, olores, humores, cambios atmosféricos y climáticos, sueños y malestares, son vehículos de información. A menudo, estos signos crean imágenes sensoriales complejas:

\section{Cuando al atardecer}

La luz se vuelve de color verde-amarillo

Y los animales están quietos

Y hay llovizna,

Este es un signo delicado.

Esta información, que atraviesa el cuerpo y el mundo, desencadena inmediatamente acciones de prevención y promoción de la salud. La repetición de fórmulas que evocan estados físicos y psicológicos, como "enfriar", "aliviar", "estar rodeado por el aliento de vida que dispersa el cansancio, la preocupación, la rabia" y que "vuelve todo calmo, tranquilo, frío" activa la imaginería e integración sinestésica que se reflejan en primer lugar en un cuerpo-mente sosegado. Además, el habla hace de esta práctica una actividad fundamentalmente social. Ramón recuerda cómo empezó a mambear porque no le daba tristeza ver a su padre mambear solo, sin nadie que lo escuchara y le respondiera. Incluso cuando 
un anciano habla solo no se trata de un soliloquio, sino de un diálogo con otros seres a nivel espiritual. A través del habla, el efecto de "enfriar" se difunde del cuerpo individual al cuerpo social y al ambiente, enlazando así la agencia personal y el bienestar generalizado.

Durante mi colaboración con Ramón y otros individuos de la Gente de Centro, tuve que familiarizarme con una serie de reglas tácitas que rigen la adquisición y transmisión del conocimiento: como Ramón lo explicó, tuve que aprender a aprender. Ya que para la Gente de Centro todo conocimiento ya está dado, el aprendiz no construye conocimiento, sino que lo halla a través de una búsqueda personal que es simultáneamente un proceso de autodescubrimiento y de autoformación. Por consiguiente, la transmisión del conocimiento es típicamente no intrusiva y se evitan deliberadamente explicaciones didácticas directas. Sin embargo, la transmisión del conocimiento está lejos de no ser articulada. El soporte para el aprendizaje está meticulosamente organizado, y se utilizan sofisticadas estrategias pedagógicas que fomentan el método heurístico, el estado de alerta y la capacidad de introspección del aprendiz. El aprendizaje siempre es sensible a las circunstancias empíricas con las que dialoga, y por lo tanto puede ocurrir inesperadamente. Las personas disfrutan de la naturaleza impredecible de la transmisión-adquisición del conocimiento, y advierten al aprendiz que esté siempre alerta.

Diferentes tipos de estrategias verbales se utilizan de acuerdo con el propósito a la mano. Dos amigos de las etnias Uitoto y Muinane, respectivamente, produjeron el siguiente repertorio, que pude confirmar con otros interlocutores:

1. La metáfora sirve para decir de todo en una cosa, de una manera intencionalmente no directa.

2. Consejo: esto es directo. Es más fácil anotarlo. Similar a:

3. Orientación. Esta es una palabra dulce.

4. Canto: ¡cuántas cosas se dicen a través de canciones! [Las canciones, por ejemplo, se utilizan para expresar críticas en 
un ritual de la danza. Las competencias del conocimiento mitológico también implican duelos de adivinanzas].

5. Manguaré [tambores].

6. Signos [gestos]: tienen otra función...

7. Conjura: no es hablada ni cantada; es soplada. No se puede escribir porque hay dos caminos que se cruzan: el bien y el mal. Se utiliza para curar. Tiene poder.

8. Palabras escritas: mucha carreta. No se ha establecido su función entonces es archivada, no sirve para transmitir, para devolver el conocimiento, para hacerlo circular. Traiciona las normas del aprendizaje. ¿Para qué quiero aprender? ¿Cómo lo devuelvo? ¿Cómo lo defiendo? El que va a pagar es el maestro, y el conocimiento archivado se embolata, ya no sirve.

9. Mitología: no es de tiempo atrás, sino es circular [hacen un mudra uniendo el dedo pulgar e índice en un círculo]: del pasado al presente al futuro. Palabra de Vida, o mejor dicho, Palabra de Origen. Es el conocimiento del Abuelo de Tabaco. Tiene un poder de vida.

10. Leyenda o cuento: "se dice que...". Un discurso transformado por la gente. Puede tener una base mitológica pero perdió su poder. Cuando menciona lugares, estos ya no tienen poder, como lo tienen en la mitología.

11. Historias: historias de los antepasados, de lo que pasó en el pasado. Tienen un fin moral.

Luego, añadieron el siguiente comentario:

Durante el aprendizaje la gente no habla. La orientación es más difícil. Tienes que aprender a regañar, sí, pero con una palabra dulce. ¿No sabes qué energía se transmite por medio del lenguaje? El consejo, en cambio, es para despertar dudas de una vez. Pero todo tiene su propio tiempo. [La palabra de] consejo, por ejemplo, tiene tres fases: discusión, consejo y proyección para el trabajo, de lo contrario le falta algo, retrospectivamente no fue una buena idea, una palabra de vida. Decimos "ponerlo 
en tierra de amanecer". Es por ello que estamos despiertos toda la noche, para enfriarlo todo.

La obsesión de la Gente de Centro con las clasificaciones parece contradecir el hecho de que las clasificaciones tienen una manera de mutar, de esquivar cualquier intento de normalización. Parece que, como dicen Maturana y Varela: "El conocimiento nos obliga a asumir una actitud de constante vigilancia hacia la tentación de la certidumbre" (1984, p. 245). El significado es simultáneamente revelado y re-velado, y, al igual que el gato de Cheshire, desaparece, dejando atrás solo el rastro de una sonrisa. Esto puede ser frustrante, como muestra el siguiente extracto de mi diario de campo.

[...] Esta noche comenzaron con el consejo. Vinieron aquí para interrogarme. ¿Pero sobre qué? Ellos no lo han dicho.

Dicen que el diálogo debe tener un tema, una pregunta no formulada. De lo contrario, el pensamiento se confunde.

"Quédate quieto. No te molestes con los mosquitos. No te muevas. Ni siquiera si tienes que orinar, o si tu cuerpo duele... Si te mueves, no me dejas escuchar al Padre Creador [...]".

- “¿Cuántos niveles hay?”

Me están interrogando sobre el tema "etapas de una conversación”. Al menos eso es lo que pensaba. Yo creía que el tercer nivel era "ponerlo en la tierra del amanecer" (es decir, "proyección"), pero estoy equivocada. Estaba casi segura y lo dije con confianza.

- "No!".

No. Se miran el uno al otro.

- ¿No?"

- "Estás empezando por el quinto".

$¿$ El quinto? ¿No eran tres? Desde el quinto, ahora estoy retrocediendo. Sin siquiera darme cuenta, cambié de clasificación y de dirección. Desde el quinto nivel, el de jojo!, "vulgaridad", me muevo hacia abajo. Sí, el nivel más importante está abajo, como un pensador sentado:

5. Vulgaridad

4. Diplomático 
3. Aprendiz de líder

2. Mitología por historias

1. Mitología por orígenes

Pero este es otro camino. Se cruzaron como las fibras de un canasto. El pensamiento que no queda atrapado se escurre.

Para la Gente de Centro, el que sabe, nunca dice "yo sé". E1 conocimiento se disimula por razones que van más allá de la modestia. Además del poder del conocimiento de producir efectos tangibles, esto tiene que ver con el valor atribuido a la heurística y al pensamiento lateral o divergente. La imagen del canasto es usada a menudo por la Gente de Centro para describir el conocimiento como algo que se teje. Más que una metáfora, esta imagen guía la acción performativa del conocimiento, actividad tanto creativa como restringida, texturizada y relacional, que sigue un patrón estructurado pero que al mismo tiempo es emergente.

La interpretación de signos está orientada, incluso construida, por el habla. Ochs y Capps (1996, p. 19) han señalado el papel de las narrativas en dar forma a la experiencia "imponiendo orden" y creando "una continuidad entre mundos pasados, presentes e imaginados". Pero, integradas en las narrativas, otras formas de comunicación, como el gesto y la postura, el silencio y hasta los sonidos de los animales, crean fisuras y tensiones en ese orden y en esa continuidad, y es precisamente de esta disonancia que emerge el significado. Esto muestra cómo un método investigativo que privilegia la recolección de enunciados verbales queda limitado en la tarea de tender un puente con el conjunto de experiencias de la gente con la que estamos investigando y su propia percepción del contexto, que como nos recuerda Fabian (1995), no está dado, sino es producido. Alfredo Molano describe la disonancia entre datos y experiencia vivida de la siguiente manera: "Para mí, el trabajo de campo valía por las numerosas perspectivas que abría y las sorpresas que guardaba, y no por la información recogida. Que, por lo demás, una vez sistematizada, 
subrayaba de nuevo la diferencia con lo que en la trastienda los entrevistados dejan ver y permiten sentir" (2011, p. 101).

\section{La etnografia en una encrucijada}

La intelectualización y racionalización crecientes no significan, pues, un creciente conocimiento general de las condiciones generales de nuestra vida. Su significado es muy distinto; significan que se sabe, o se cree que en cualquier momento se puede llegar a saber, que no existen en torno a nuestra vida poderes misteriosos o imprevisibles, sino que, por el contrario, todo puede ser dominado mediante el cálculo y la previsión. Pero esto significa el desencantamiento del mundo. Max Weber, El politico y el cientifico.

¿Qué es el mundo encantado? ¿Cómo investigar en un mundo encantado, y por qué? Para mí, el mundo encantado es un mundo que excede y resiste el desencantamiento del mundo. Lo excede porque sobrepasa los límites de una comprensión del mundo fundada en la separación entre objeto y sujeto, mente y cuerpo, naturaleza y sociedad. Lo resiste porque se niega a ser convertido en un objeto manipulable, cuantificable y controlable. Al entrar en un mundo encantado, la autoridad del saber académico queda automáticamente revocada. En cuanto reconocemos su existencia, tomamos consciencia de que el conocimiento no es definitivo; nos quedamos con el conocimiento que "se vive y se siente". Esto nos obliga a asumir una actitud responsable hacia el mundo que el acto de conocer produce o puede producir. En una academia siempre más alienada de la vida real, en donde el conocimiento se evalúa por indicadores de producción y factores de impacto, no es un asunto menor recordarnos, como hacen los indígenas, que el conocimiento tiene efectos directos sobre el mundo. 
Desde el giro crítico en la antropología, la labor etnográfica entraña una reflexión sobre lo que se está haciendo y cómo -a menudo resultado no de una toma de conciencia ética o política sobre nuestras herramientas analíticas y nuestro poder de representar al otro, sino de frustraciones y contratiempos-y sabemos por experiencia que investigar es una práctica intersubjetiva que implica aventurarse por caminos culebreros y a veces fortuitos, que subvierten lo planeado. Sin embargo, mientras esta reflexión involucre únicamente nuestras propias prácticas investigativas y nuestra posición como investigadoras, termina reafirmando la asimetria entre un sujeto que estudia y un objeto que es estudiado, y el quehacer etnográfico queda reducido a la descripción y explicación de la cultura de los otros; es decir, sale inmune del encuentro etnográfico. Para quebrar esta asimetría, la labor etnográfica debería volverse más sensible a los métodos y las teorías del conocimiento de nuestros interlocutores, quienes a su vez nos investigan. La praxis investigativa no está por encima del conocimiento producido y validado en este lugar compartido. Existen en la actualidad muchas propuestas encaminadas a descolonizar el método de investigación: etnografia en colaboración, etnografia compartida, investigación-acción participativa, diálogo de saberes, entre otras. Pero este objetivo no puede lograrse sin una atención generosa a los fines y medios de la investigación, tal como nuestros interlocutores los perciben y los entienden, sus teorías y prácticas concretas del conocimiento, sus epistemologías. Es desde allí que debe surgir un cuestionamiento profundo del significado y los modos de participación y diálogo en otros ámbitos culturales, hecho sin el cual participación y diálogo siguen siendo impuestos desde arriba. La participación solo puede lograrse a medida que la práctica investigativa se comprometa con otras prácticas cognitivas y renuncie a su posición de control.

Al lado de estas propuestas, las metodologías indígenas académicas han logrado recientemente un lugar de relieve en el panorama de los enfoques decoloniales de pesquisa (Smith, 1999; Louis, 2007; Kovach, 2009). Estos trabajos se enfocan, principalmente, en los principios que conectan la metodología a las visiones 
del mundo de los grupos indígenas. Por ejemplo, señalan que el paradigma de investigación indígena se basa en la convicción de que el conocimiento es relacional, no simplemente una relación interpersonal, sino una relación con todo el cosmos. La metodología indígena no está preocupada por cuestiones de validez o confiabilidad, sino con cómo cumplo mi papel en esta relación, cuáles son mi obligaciones (Shawn, 2001). Sin embargo, estos trabajos no brindan mayor detalle sobre las prácticas cognoscitivas concretas de los indígenas. Si reconocer los saberes de los otros implica estar dispuestos a derribar el edificio metodológico occidental, son estas prácticas las que pueden enseñarnos otras maneras de hacer investigación.

La presente reflexión surgió de las preguntas: ¿cuáles son los aportes de las metodologías indígenas al quehacer etnográfico?, ¿cómo pueden influir en las ciencias sociales las metodologías que surgen del diálogo intercultural? Los ejemplos brindados aquí sugieren algunos aprendizajes. Primero, que el método moderno desencantado -con sus "entrevistas semi-estructuradas", sus grupos focales y sus diseños de recolección de datos- es inadecuado para dar cuenta de un mundo en que todo habla y lo hace de manera inesperada. Segundo, que para poder contribuir a la reafirmación del conocimiento cultural indígena -que juega un papel clave en los actuales procesos de afirmación política-, la práctica etnográfica no puede limitarse a documentar contenidos, sino que, en un verdadero sentido de interculturalidad, tiene que dejarse ocupar por estas otras metodologías. Tercero, que la advertencia de los indígenas a no boletear el conocimiento es un llamado a repensar el actual mundo académico preocupado por publicar a toda costa.

Quisiera concluir con las palabras de Tim Ingold:

[La antropologia] no es tanto un estudio de personas y cosas como una forma de pensar con ellas: una clase magistral prolongada en la que el novicio aprende a percibir las cosas de la manera en que lo hacen sus mentores [...]. Es unirse a la gente en 
sus especulaciones acerca de lo que la vida puede o podría ser, en formas sin embargo fundamentadas en una comprensión profunda de lo que la vida es en momentos y lugares particulares. (2013, p. 4, traducción mía)

\section{Referencias}

Basso, K. (1996). Wisdom Sits in Places: Landscape and. Language among the Western Apache. Albuquerque: University of New Mexico Press.

Deloria, V. Jr. (1999). Spirit and Reason. The Vine Deloria Jr. Reader. Golden CO.: Fulcrum Publishing.

Fabian, J. (1995, mar). Ethnographic Misunderstanding and the Perils of Context. American Anthropologist, 97(1), 41-50.

Griffiths, T. (2002). Finding One's Body: Relationships between Cosmology and Work in North-West Amazonia. En L. Rival y N. L. Whitehead (Eds.), Beyond the Visible and the Material. The Amerindianization of Society in the Work of Peter Rivière (pp. 247-262). Oxford: Oxford University Press.

Hester, L. y Cheney, J. (2001). Truth and Native American Epistemology. Social Epistemology, 15, 319-334.

Ingold, T. (2013). Making: Anthropology, Archaeology, Art and Architecture. London: Routledge.

Ingold, T. (2014). That's Enough About Ethnography! Hau: Journal of Ethnographic Theory, 4(1), 383-395.

Kovach, M. (2009). Indigenous methodologies: Characteristics, conversations, and contexts. Toronto: UT Press. 
Louis, R. P. (2007). Can You Hear us Now? Voices from the Margin: Using Indigenous Methodologies in Geographic Research. Geographical Research, 45(2), 130-139.

Maturana, H. y Varela, F. (1984). The Tree of Knowledge. The Biological Roots of Human Understanding. Boston - London: Shambhala.

Micarelli, G. (2015a). Divine Banknote: The Translation of Project Money into Public Wealth. En F. Santos-Granero (Ed.), Images of Public Wealth: Property, Identity, and Wellbeing in Native Amazonia (pp. 161-187). Tucson: University of Arizona Press.

Micarelli, G. (2015b). Indigenous Networks at the Margins of Development. Bogotá: Editorial Universidad Javeriana.

Molano Bravo, A. (2011). La gente no habla en conceptos, a menos que quiera esconderse. Revista Anthropos: Huellas del Conocimiento, (230), 101-106.

Ochs, E. y Capps, L. (1996). Narrating the Self. Annual Review of Anthropology, (25), 19-43.

Shawn, W. (2001). What is indigenous research methodology? Canadian Journal of Native Education, 25(2), 175-179.

Smith, L. T. (1999). Decolonizing Methodologies: Research and Indigenous Peoples. New York: Zed Books.

Stoller, P. (1997). Sensuous Scholarship. Philadelphia: University of Pennsylvania Press.

Varela, F., Thompson, E. y Rosch, E. (1991). The Embodied Mind. Cambridge, MA: MIT Press.

Viveiros de Castro, E. (2010). Metafisicas caníbales: Líneas de antropología postestructural. Buenos Aires: Conocimiento.

Weber, M. (1975). El politico y el cientifico. Madrid: Alianza. 
White, H. (2002, sep). Strategies and Identities by Mobilization Context (Working Papers). Nueva York: Center on Organizational Innovation, Columbia University.

\section{Cómo citar este artículo}

Micarelli, G. (2018). Investigar en un mundo encantado: los aportes de las metodologías indígenas al quehacer etnográfico. Universitas Humanística, 86, 219-245. https://doi.org/10.11144/Javeriana.uh86.imei 